\title{
Research development in doctoral education: role of languages and cultures
}

\section{Susana Pinto}

Research Centre Didactics and Technology in the Education of Trainers, University of Aveiro, Portugal.

\begin{abstract}
Portuguese universities have been receiving an increasing number of students from Portuguese-Speaking Countries at the level of PhD studies, namely from Brazil, Angola, Cape Verde and Mozambique. As acknowledged by research, undertaking a PhD overseas entails several challenges and one of the deepest concerns the implications of languages and cultures in several doctoral activities, since they act as significant research reconfiguration agents. Against this background, this paper reports on a study that aimed at understanding the role of languages and cultures in doctoral research development. For this matter, and within a qualitative approach, semistructured interviews were conducted with doctoral students from PortugueseSpeaking Countries attending a Portuguese university. Results from thematic analysis reveal that students' linguistic and cultural backgrounds influence several stages of the research process: theme and research objetives definition, theorisation of the research problem and concept mobilisation, construction of data collection instruments and data collection and thesis writing. Implications of findings for institutional policy and practice concerning doctoral education and research are put forward.
\end{abstract}

Keywords: Portuguese higher education; doctoral research development; international doctoral students; languages and cultures. 


\section{Introduction}

Globalisation and internationalisation have been posing several challenges to Higher Education Institutions (HEI) worldwide. One of the biggest challenges concerns the increase flow of international students (UNESCO, 2018), namely within doctoral programmes, which brings forth questions concerning the encounter of different languages and cultures in educational and research activities. In Portugal, recent national policies have led to an increase of international students in HEI (DGEEC, 2018). Within those policies, an emphasis has been put on the need to attract international students particularly from the Community of Portuguese-Speaking Countries (CPLP). Students from the CPLP represent the most numerous group among foreign students attending HEI in Portugal, due to strong historicalcultural ties and the existence of special access regimes within cooperation agreements. In 2017/2018 about two-thirds of international students came from the CPLP mainly Brazil, Angola, Cape Verde and Mozambique (DGEEC, 2018). This increase is noticeable not only at under graduation and master levels but also at $\mathrm{PhD}$ programmes: since 2005/06 there has been a growth in the number of $\mathrm{PhD}$ students from the CPLP at a cumulative annual rate of almost 30\%. In 2011/2012, 12.3\% of total students attending doctoral programmes were from the CPLP, mainly from Brazil and Angola, and in 2017 23\% of the graduated doctoral students enrolled were international and came mostly from Brazil, Angola, Mozambique and Cape Verde (PORDATA, 2019).

This has not been accompanied by a shared reflection and discussion among the Portuguese academic community concerning the challenges faced by these students, namely regarding the role of languages and cultures in doctoral research activities. Some studies have been acknowledging that pursuing a $\mathrm{PhD}$ in a foreign context brings forth critical challenges related to languages and cultures which play a very important role as reconfiguration agents influencing all stages of research: reading literature and theorising the research problem (Robinson-Pant, 2017); construction of data collection instruments and interpreting data (Araújo e Sá et al., 2020); writing the thesis and thesis viva (Doyle et al., 2017); disseminating findings (Pinto \& Araújo e Sá, 2020a). In Portugal, studies focusing on the challenges of researching across languages and cultures in doctoral education are almost inexistent. With the aim of exploring the experience of doing a doctorate at a Portuguese $\mathrm{HEI}$, and focusing on four doctoral programmes in the area of the humanities and social sciences, Araújo e Sá et al. (2020) interviewed international doctoral students from African Portuguese-Speaking countries. Findings show that languages and cultures influence the acquisition of the language of the discipline, research dissemination, and thesis-writing. Likewise, Pinto \& Araújo e Sá (2020b), in a study that aimed to shed light on what it means to research across languages within doctoral education, concluded that CPLP international students' linguistic and cultural heterogeneity are not acknowledged by supervisors as 
mediation and reconfiguration agents of the research process, instead being perceived as problematic.

\section{Methods}

\subsection{Research question and institutional context}

This paper aims answering the following research question: what is the role of languages and cultures in doctoral research development in the voices of students from the CPLP attending a Portuguese university? A qualitative case study was undertaken in the Department of Education and Psychology (DEP) of the University of Aveiro (UA, Portugal) in 2018. In 2017/2018 the UA was attended by 1132 international students (total number of about 13.000 students): 236 in graduation degrees, 373 in master's and 536 in $\mathrm{PhD}$ programmes. 57\% of the foreign students enrolled in PhD programmes were from the CPLP, mainly from Brazil as perceived in Table 1:

Table 1. Nationality of CPLP students enrolled in PhD Programmes at the UA (2017/2018).

\begin{tabular}{lc}
\hline Nationality & N. of students \\
\hline Brazil & 202 \\
Angola & 43 \\
Cape Verde & 27 \\
Mozambique & 24 \\
East Timor & 8 \\
Sao Tome and Principe & 2 \\
Guinea Bissau & 1 \\
\hline
\end{tabular}

In 2017/2018, the DEP had 220 students attending its four doctoral programmes and 39\% were foreign students. $86 \%$ of the foreign students were from the CPLP $(n=74)$, as shown in the following table: 
Table 2. Students attending the DEP's PhD Programmes (2017/2018).

\begin{tabular}{lccc}
\hline PhD Programmes & $\begin{array}{c}\text { Total n. of } \\
\text { students }\end{array}$ & $\begin{array}{c}\text { Foreign } \\
\text { students }\end{array}$ & $\begin{array}{c}\text { CPLP } \\
\text { students }\end{array}$ \\
\hline PhD Programme in Education & 128 & 62 & 54 \\
PhD Programme in Multimedia in Education & 59 & 21 & 17 \\
PhD Programme in Psychology & 17 & 2 & 2 \\
PhD Programme in Gerontology and Geriatrics & 16 & 1 & 1 \\
& $\mathbf{2 2 0}$ & $\mathbf{8 6}$ & $\mathbf{7 4}$ \\
\hline
\end{tabular}

The $\mathrm{PhD}$ Programme in Education, the focus of this study, had the largest percentage of foreign students: $48 \%(\mathrm{n}=62)$. Of these, $87 \%$ came from Portuguese-Speaking Countries ( $\mathrm{n}$ =54): Brazil $(\mathrm{n}=26)$, Angola $(\mathrm{n}=21)$, Mozambique $(\mathrm{n}=5)$, East Timor $(\mathrm{n}=1)$ and Sao Tome and Principe $(\mathrm{n}=1)$.

\subsection{Participants, data collection and analysis}

Twelve PhD students were interviewed (semi-structured interviews of 45 to 70 minutes). Interviews were conducted in Portuguese, audio recorded and transcribed. Following the General Data Protection Regulation of the European Union (Regulation 2016/679), all participants were informed of the research objectives and how data might be used and were guaranteed that all data would be treated confidentially and anonymously. Students were selected according to some criteria: active enrollment for at least three years in the $\mathrm{PhD}$ Programme in Education, and thesis completion in 2017/2018 or near completion. Three students had finished their $\mathrm{PhD}$ and nine were finishing. Six were male and six were female and were aged between 33 and 60 years. Six came from Angola, three from Brazil, two from East Timor and one from Mozambique. Their mother tongues were very diverse: Portuguese (five students), Kimbundu (two), Nhungué (one), Umbundu (one), Kikongo (one), tetum (one) and Indonesian (one). Six of them were conducting the empirical study in Angolan context, three in Portuguese context, two in East Timor and one in Mozambique.

The interviews were submitted to thematic analysis (Clarke \& Braun, 2013), informed by an iterative process that combined a systematic and rigorous analysis of transcripts with literature review. The themes that emerged were the following (Table 3): 
Table 3. Themes - data analysis.

\begin{tabular}{cc}
\hline $\begin{array}{c}\text { Theme and research objetives definition } \\
\text { Role of languages and } \\
\text { cultures in doctoral } \\
\text { research }\end{array}$ & $\begin{array}{c}\text { Theorisation of the research problem and concept } \\
\text { mobilisation }\end{array}$ \\
Construction of data collection instruments and data \\
collection \\
Thesis writing
\end{tabular}

\section{Findings}

Findings are structured according to the themes of analysis and data are presented and discussed by providing an account of participants'voices. Statements are illustrated by quotes which give representative perspectives of the larger group of participants.

\subsection{Theme and research objetives definition}

The ways linguistic and cultural backgrounds intervene in the definition of themes and research objetives are underlined by nine students from Angola, Mozambique and East Timor. All these students were conducting their empirical studies in their countries and the themes were defined according to contextual needs that they identified from their professional experiences as teachers, heads of higher education departments, employees of Ministries of Education. In this sense, research objetives were aimed at analysing and improving contextual features, as perceided in the following quote:

I study practices of learning assessment of Angolan teachers. I'm a teacher and I want to contribute to assist teachers in my country in assessing students' learning. (ST2)

This is a trend very much observed in doctoral students coming from African countries who perceive the opportunity of taking their $\mathrm{PhD}$ abroad as an opportunity to contribute to their countries' development (Doyle et al., 2017).

\subsection{Theorisation of the research problem and concept mobilisation}

Five students highlighted the role of languages and cultures in the theorisation of the research problem and in concept mobilisation. Regarding the first aspect, students emphasised that the construction of conceptual frameworks requires mastering English:

Most scientific articles about East Timor are in English. There are only a few in Portuguese. So, I have to make a big effort to read in English. (ST4) 
One student, whose mother tonge is not Portuguese, emphasised that reading literature in Portuguese was quite important for her research but extremely difficult:

I used to proceed this way: I read the articles in Portuguese, then I translated them into my mother tongue, and then I wrote a synthesis which I translated back into Portuguese. (ST8)

Concerning concept mobilisation, students' voices emphasised a need for negotiation between culturally inflected ways of knowledge (Manathunga, 2017). This is noticeable, for instance, when a student wanted to focus his thesis on a concept which supervisors had never heard about:

My supervisors asked: "What is tarabandu?". I explained it is a traditional law to ensure environment and agricultural protection. It is a Timorese concept. At first, they did not understand. So, I looked for papers in English to give them and they understood and accepted the focus on this concept. I was glad I taught them a new concept. (ST4)

This example reveals that the encounter of different research cultures in doctoral research may enhance mutual transformative learning by acknowledging students' different academic knowledge traditions and contexts.

\subsection{Construction of data collection instruments and data collection}

Eight students underlined the implications of languages and cultures in the construction of data collection instruments to be applied in their origin contexts. Issues of terminology and local validation arose in their voices:

When we discussed the survey, I said: "Maybe in Portuguese that is correct, but in East Timor it is not like that. My students will not understand those words!" After explaining, my supervisor understood. (ST8)

Brazilian students, who are doing their research in the Portuguese context, posed questions regarding Portuguese language varieties:

I wrote the interview guide in European Portuguese because there are differences in relation to Brazilian Portuguese. If I ask "For how long did you take 'mamadeira' [bottle of milk], a Portuguese person will not understand, I have to use the word 'biberão'. (ST3)

Cultural and social issues were also emphasised in the construction of data collection instruments, with students explaining negotiation processes with their supervisors, as perceived in the following example:

In the construction of the questionnaire, we discussed whether housewife is a profession. In Angola it is considered a profession. But my supervisors did not understand. I explained this and then they understood. (ST9) 
In what data collection is concerned, two Brazilian students highlighted an ideological perspective on language and culture related to Portuguese language varieties and their prestige, which hinders data collection process:

I have faced problems with my data collection in schools. I realised that my supervisor had no problem with data collection. I thought this happened because she was a higher education professor. But today I know that it happens because I am Brazilian. (ST3)

\subsection{Thesis writing}

As literature suggests, academic writing is difficult for all doctoral students, but it becomes much more demanding when students and supervisors have to deal with writing across different cultural and linguistic backgrounds (Doyle et al., 2017). Ten students underlined the impact of language proficiency in thesis writing. For those whose mother tongue is not Portuguese, the emphasis was on the difficulties concerning grammar, syntax and ortography which cause anguish and distress:

Speaking Portuguese and writing in Portuguese is quite different. My thoughts are done in my mother tongue and only then in Portuguese. My linguistic spontaneity only exists when I'm using my mother tongue. Writing, grammar, spelling... this is a new learning step and every day I'm learning to write European Portuguese. (ST1)

Students whose mother tongue is Portuguese emphasised the clash between Portuguese language varieties, namely European and Brazilian, as stressed in the following quote:

Although we all speak Portuguese, we do not speak the same Portuguese. If we don't speak the same Portuguese, we don't write the same way, naturally. This is very frustrating. (ST11) In spite of this, students feel that they must write their thesis in European Portuguese, recurring to paid revisions or to the help of colleagues and supervisors, emphasising the fear they have that the jury in the thesis viva might see this as a problem:

I will write in European Portuguese and then ask for a linguistic revision because of the jury. When I presented my project, an examiner said: "Before I saw your CV, I already knew that you were Brazilian". So, I am afraid that there may be some comments on my writing. (ST12)

\section{Discussion and research implications}

Findings show that languages and cultures influence several activities of doctoral research development, acting as research reconfiguration agents (Robinson-Pant, 2017). Mainly, this influence is perceived by students in thesis writing, in the definition of the theme and research objetives and in the construction of data collection instruments. While the influence on the two latter research activities seems to be almost innocuous, the impact on thesis writing is 
problematic causing students' anxiety and linguistic insecurity. This issue has a double facet: on one hand, the difficulties felt by non-native speakers of Portuguese who need institutional support in order to develop academic writing skills; on the other hand, the frustration and distress felt by speakers of other varieties of Portuguese who realise that their varieties may not be accepted. Nevertheless, data reveal that these students were agentic and reflexive about their doctoral research activities and were able to engage their supervisors in critical discussions leading to the recognition of their linguistic and cultural backgrounds. Students' voices underline the need for supervisors and host institutions to recognise contextually inflected modes of research development as a way of opposing to "an epistemological hegemony of the academic space wherein the so-called knowledge elites position themselves as the only legitimate producers of knowledge" (Pinto \& Araújo e Sá, 2020b, p. 15).

In the light of these results, it is important that HEI and, specifically, supervisors deepen knowledge concerning students' contexts and knowledge traditions since knowledge is culturally, historically and geographically situated (Manathunga, 2017). This requires supervisors' training for intercultural doctoral supervision which may contribute to research promoting plural perspectives, by encouraging students to draw upon their own linguistic and cultural knowledge in doctoral studies.

\section{Acknowledgements}

This work is financially supported by: National funds through the Fundação para a Ciência e a Tecnologia, IP under the project UIDB/00194/2020 and in the scope of the framework contract foreseen in the numbers 4, 5 and 6 of the article 23, of the Decree-Law 57/2016, of August 29, changed by Law 57/2017, of July 19.

\section{References}

Araújo e Sá, M.H., Costa, N., Guerra, C., Lopes, B., Lourenço, M., \& Pinto, S. (2020). University of Aveiro, Portugal. In M. Byram \& M. Stoicheva (Eds.), The doctorate experience in Europe and beyond (pp. 15-51). Routledge.

Clarke, V., \& Braun, V. (2013). Teaching thematic analysis: Overcoming challenges and developing strategies for effective learning. The Psychologist, 26(2), 120-123.

DGEEC (Direção-Geral de Estatísticas da Educação e Ciência). (2018). Principais resultados do RAIDES 17 - mobilidade internacional inscritos 2017/18. Lisboa: DGEEC.

Doyle, S., Manathunga, C., Prinsen, G., Tallon, R., \& Cornforth, S. (2017). African international doctoral students in New Zealand: Englishes, doctoral writing and intercultural supervision. Higher Education Research \& Development, 37(1), 1-14. doi: 10.1080/07294360.2017.1339182 
Manathunga, C. (2017). Intercultural doctoral supervision: The centrality of place, time and other forms of knowledge. Arts \& Humanities in Higher Education, 16(1), 113-124. doi: $10.1177 / 1474022215580119$

Pinto, S. \& Araújo e Sá, M. H. (2020a). Scientific research and languages in Portuguese Higher Education Institutions. Language Problems and Language Planning, 44(1), 20 44. doi: 10.1075/lplp.00054.pin

Pinto, S., \& Araújo e Sá, M. H. (2020b). Researching across languages and cultures: a study with doctoral students and supervisors at a Portuguese University. European Journal of Higher Education, 10(3), 276-293. doi: 10.1080/21568235.2020.1777449

PORDATA (2019). Foreign students enrolled in higher education. https:/www.pordata.pt/en/Europe/Foreign+students+enrolled+in+higher+education+(IS $\mathrm{CED}+5+8)+(2000+2012)-1313$

Robinson-Pant, A. (2017). From cross-cultural to intercultural. An alternative perspective on the research process. In A. Robinson-Pant \& A. Wolf (Eds.), Researching across languages and cultures (pp. 1-19). Routledge.

UNESCO. (2018). Global flow of tertiary-level students. http://uis.unesco.org/en/uisstudent-flow 